International Journal of Instruction e-ISSN: 1308-1470 • www.e-iji.net

Article submission code: 20201029075250

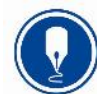

October $2021 \bullet$ Vol.14, No.4

p-ISSN: 1694-609X

pp. $155-172$

Received: 29/10/2020

Revision: 28/02/2021
Accepted: 24/03/2021

OnlineFirst: 08/07/2021

\title{
Language Learning Strategies, English proficiency and Online English Instruction Perception during COVID-19 in Peru
}

\section{Walter Miguel Fernandez Malpartida}

Prof., Professional Translation and Interpretation Program, Universidad Peruana de Ciencias Aplicadas, Peru,pctrwfer@upc.edu.pe

The research's main objectives were to develop a longitudinal assessment of students' use of language learning strategies, examine their English proficiency and report their perception of online English instruction during the new normal in Lima-Peru. The sample involved 50 undergraduate students who participated in an online high intermediate English course during 16 weeks. A mix-method research was established based on the sample size and the research questions. For the quantitative part, two comparative groups were evaluated using two instruments which were chosen from the literature review: (a) the Oxford (1990) Strategy Inventory for Language Learning (SILL), and (b) the Oxford placement test which measures English proficiency. The findings revealed that both groups reported both weak and strong language learners, and metacognitive strategies were the highest used among them. Also, the group of students who actively practiced LLS activities not only increased their overall LLS use but also improved their English proficiency. With regard to the qualitative part, a phone call interview design was implemented to 10 participants who generally reported a positive experience in terms of teaching support, feedback quality, participation and class recording availability.

Keywords: language learning strategies, English proficiency, SILL, OPT, online English instruction, COVID-19

\section{INTRODUCTION}

The world has turned upside down since the emergence of COVID-19 which has resulted in a global economic disaster, social distancing policies, and public health new challenges (Louis-Jean \& Cenat, 2020; Thapa, Rai, Adhikari, Ghimire, Limbu, Joshi \& Adhikari, 2020). The predominant face-to-face higher education system has also been greatly affected by the new normal. Universities have cancelled their face-to-face classes, graduations, examinations and they are implementing fully online programs. This transition presents new challenges when it comes to (a) course planning which requires new materials design and assessment (b) access to modern devices such as laptops, tablets and smartphones (c) students' connectivity access (d) students'

Citation: Fernandez-Malpartida, W. M. (2021). Language learning strategies, English proficiency and online English instruction perception during covid-19 in Peru. International Journal of Instruction, 14(4), 155-172. https://doi.org/10.29333/iji.2021.14410a 
engagement and participation (e) teacher tech training so as to effectively use all the new teaching resources (Demuyakor, 2020; Murphy, Eduljee \& Croteau, 2020; Toquero, 2020). Although there has never been a global consensus regarding online instruction principles, the COVID-19 crisis has triggered the exchange of global resources and research to allow the continuity of higher education. The transition from traditional to online delivery instruction also comes with some challenges such as appropriate internet bandwidth, access to internet in remote areas and virtual education skillsets (Crawford, Butler-Henderson, Rudolph, Malkawi, Glowatz, Burton, Magni \& Lam, 2020). Additionally, Lin, Zhang and Zheng (2017) claim that language courses are the most challenging among other online courses. They argue that online language learners seem to actively use learning strategies; and promoting the use of online learning strategies can ameliorate students' language achievement. Other studies show that language learning strategies and English proficiency have been mainly researched in face-to-face higher education settings (Alhaysony, 2017; Taheri, Sadighi, Bagheri \& Bavali, 2020).

\section{Online Education}

Santoveña-Casal and Bernal-Bravo (2019) point out that the current digital society requires new educational models that promote learner's interaction. The interaction between the teacher, students and course content is crucial in online courses. Interaction between students can also affect their level of satisfaction. Burdina, Krapotkina and Nasyrova (2019) argue that distance education is used when the teacher and the student are not in the same geographical area; this can give access to education to students with special needs and medical conditions. The teacher's mentor role and authority remains in the perception of students even in online scenarios. Effective computer skills are needed from both the teacher and students so as to work in distance instruction. The communication and interaction between the teacher and the student can be established synchronously, such as videoconferencing that allows direct contact. Or communication can also be done asynchronously, when interaction is not simultaneously allowing students to have more time for feedback and being evaluated. Tao, Zheng, Lu, Liang and Tsai (2020) claim that in contrast to traditional face-to-face learning scenario, studying in an online context requires students to be always ready to participate in the virtual tasks, they also have to be more responsible to monitor their process of learning, in other words, online students need to develop their self-regulating skills such as setting goals, seeking help and self-evaluation. Similarly, Demuyakor (2020) argues that learners can benefit from their online learning experience since successful online learners are both autonomous and organized; but, online education has some drawbacks such as students' frustration, course content credibility and resources readiness. Furthermore, Dhawan (2020) points out that the strengths of online learning are time and location flexibility, course content availability and immediate feedback. Some weaknesses can be the technical difficulties, management of time, distractions, students' confidence level, frustration and anxiety. The opportunities are designing a variety of programs, including problem-solving skills such as critical thinking and adaptability, applying new methodologies. And the challenges are achieving students' engagement, course content 
delivery and quality control, investment in proper equipment and tech training, guarantying internet and Wi-Fi access.

\section{English Proficiency}

According to Daif-Allah and Aljumah (2020) there are more than one billion people who speak English either as a native language, foreign language or second language. It is the international language of communication, business, government, and entertainment. It is frequently taught as a foreign language (EFL) in a considerable number of countries in order to achieve educational requirements, have access to better job openings, improve English language proficiency, and other reasons. People's language proficiency is established based on their reading, writing, speaking, comprehension, grammar and lexical skills performance (Tavakoli, Rakhshanderoo, Izadpanah \& Moradi, 2014). Language proficiency refers to the extent a person is able to use a language in terms of vocabulary command, reading, writing, and both conversational and understanding skills (Arisman, 2020).

\section{Language Learning Strategies}

The definition of LLS involves the conscious reasoning and actions to make possible the process of language learning (Shakarami, Hajhashemi \& Caltabiano, 2017). LLS can also be described as processes and behaviors in order to achieve learning goals regardless of the content and context (Arisman, 2020). According to Oxford (1990) LLS are divided into direct strategies such as memory, cognitive and compensation; and indirect strategies which are metacognitive, social and affective. Memory strategies are characterized by the memory storage of information consciously in the short and long term, and its subsequent use when necessary. Cognitive strategies are also a conscious way of approaching learning, writing and taking notes, elaboration of concepts. Compensation strategies focus on reducing or overcoming gaps in the use of the new language, such as the use of the mother tongue, the use of gestures in order to express ideas. Metacognitive strategies contribute to the planning and organization of the language learning process. Affective strategies reflect the management of emotions and attitudes individually and before the social group. Finally, social strategies allow interaction and cooperation with other individuals in the learning process. Studies also suggest that the LLS taxonomy proposed by Oxford (1990) is still theoretically relevant (Iamudom \& Tangkiengsirisin, 2020; Ranjan \& Philominraj, 2020).

Some studies have established a positive relationship between LLS use and factors such as language proficiency, attitude and motivation (Habók \& Magyar, 2018; Taheri, Sadighi, Bagheri, \& Bavali, 2020). As noted by Alhaysony (2017), university students taking part in an English class mostly use both cognitive and metacognitive strategies while memory and affective are the least used. In another study, undergraduate students who were studying Foundation English courses reported highly use of metacognitive strategies in contrast to memory strategies (Rongdara, Liew, Masturah \& Kanya, 2019). Two studies revealed similar results since EFL students highly preferred metacognitive strategies while their affective strategies were the least used (Lestari \& Fatimah, 2020; Lestari \& Wahyudin, 2020). Moreover, in a university setting, it was reported that 
compensation, affective, and cognitive strategies were mostly used by high achievers; social, metacognitive, and memory strategies were mostly used by low achievers (Taheri et al., 2020). In a polytechnic school, high English proficient learners reported having a high level of compensation strategies while low English proficient learners reported a highly use of metacognitive strategies (Yustitiasari, Junining \& Sahiruddin, 2020). In another polytechnic school, the EFL students reported the cognitive and metacognitive strategies as the highest and compensation and affective as the lowest (Aziz \& Shah, 2020). In high schools, it was reported that metacognitive strategies have a strong effect on English proficiency (Habók \& Magyar, 2018). Also memory, cognitive and compensation strategies are significantly related to English proficiency (Arisman, 2020).

Although there is current research regarding LLS and English instruction as a foreign language, it is observed that most investigations have focused on a cross-sectional analysis of LLS and were conducted in face-to-face scenarios. (Arisman, 2020; Aziz \& Shah, 2020; Hastuti, Surahmat, Sutarto \& Dafik, 2020; Iamudom \& Tangkiengsirisin, 2020; Lestari \& Fatimah, 2020; Lestari \& Wahyudin, 2020; Mohammadi \& Izadpanah, 2019; Ranjan \& Philominraj, 2020; Shehzad et al., 2020; Taheri et al., 2020; Tao et al., 2020). Consequently, this study attempts to fill a gap in the literature by investigating students' LLS use from a longitudinal point of view in order to see the way LLS are used over time in an online language course (Lin, Zhang \& Zheng, 2017). Also, to examine if LLS exercises have a direct effect on English proficiency. More importantly, this is an opportunity to study LLS use, English proficiency and students' perception of their English online instruction after the emergence of COVID-19. These are the research questions:

1. Do students' LLS use change after some period of time in an online English course?

2. Which language learning strategies do students use the most in an online English course?

3. Is there any English proficiency difference between a class which is directly exposed to LLS activities and another one which is not in an online English course?

4. What is students' general impression about online English instruction during the COVID-19 lockdown?

5. What are the advantages and drawbacks of online English instruction during the COVID-19 lockdown?

\section{METHOD}

\section{Research Design}

A mix-method research (both quantitative and qualitative) was used in the study taking into consideration its research questions. The quantitative part followed a quasiexperimental design to study both the experimental and control group. For the qualitative part, a structured phone interview design was applied to students. Other studies also employed a mix-method design regarding LLS and language learning in EFL and ESL (Iamudom \& Tangkiengsirisin, 2020; Shakarami, Hajhashemi, \& 
Caltabiano, 2017; Taheri et al., 2020; Tsai, 2020). This study involved three main stages: (a) pre assessment of LLS and English proficiency (b) implementation of the LLS program in 18 sessions (c) post assessment of LLS, English proficiency, and structured phone interviews to measure students' perception of their online English instruction.

\section{Participants}

The study population consisted of undergraduate students from a private university in Lima-Peru. This institution offers students majors in Management, Business, Psychology, Engineering, Education and others. Although the university had experience implementing blended and online courses from a variety of subjects before COVID-19, most English courses were taught face-to-face. So, after COVID-19 English courses were also taught fully online (videoconference). The participants of the study were selected by applying the cluster random sampling as other studies (Hastuti et al., 2020; Mohammadi, \& Izadpanah, 2019; Tsai, 2020). The participants were part of a high intermediate English course (B2) designed to be taught during 16 weeks, students had three sessions per week, two hours each; the course began in mid-March in 2020. To enroll in this course students had to either take a placement test or pass the previous intermediate course (B1). The course is regarded as highly communicative since it focuses on speaking, writing, reading and listening tasks which ideally prepares students for a higher command of English (C1). Two groups of students, enrolled in the same online English course, were randomly chosen. One class was the experimental group, 23 participants and another the control group, 27 participants. Additionally, students' age ranged from 17 to 20 years old; both groups' command of English were quite similar.

\section{Instruments}

This study used online instruments as other studies during COVID-19 (Demuyakor, 2020; Murphy, Eduljee, \& Croteau, 2020; Thapa, Rai, Adhikari, Ghimire, Limbu, Joshi, \& Adhikari, 2020). Online surveys are not only a cheap option but also a quick alternative to get data. Online questionnaires must be designed considering the different devices people use such as PCs, smartphones, emails, links and apps; and all survey's items must be responded (Toepoel, 2017). The first instrument, the Oxford Placement Test (OPT) was used to measure learners' English proficiency. According to the Council of Europe (2020) six levels describe the foreign language proficiency: A1 and A2 (basic user), B1 and B2 (independent user), C1 and C2 (proficient user). Several studies show the validity and current relevance of the OPT (Enayat, \& Amirian, 2016; Mohammadi \& Izadpanah 2019; Tavakoli, Rakhshanderoo, Izadpanah \& Moradi, 2014). The Oxford Placement Test (2001, version 2) has two parts, the first section has 40 items, and the second 20 items. Both parts measure English proficiency from beginner level/A1 (0-17 points), elementary level/A2 (18-19 points), lower intermediate/B1 (30-39 points), upper intermediate/B2 (40-47 points), advanced/C1 (48-54 points), to very advanced/C2 (55-60 points). The OPT (2001, version 2 ) parts were transformed into a 60 -item digital version which showed all the items in random order. The digital OPT was available on the students' university platform and it was used as both the pre-OPT and post-OPT. 
The second instrument was the Strategy Inventory for Language Learning (SILL) version 7.0 (Oxford, 1990), it is regarded as the most comprehensible LLS tool (Alhaysony, 2017). The SILL was used in order to determine the use and frequency of LLS by students. This questionnaire contains 50 items and a Liker scale which range from 1 (never/almost never true of me) to 5 (always/almost always true of me). Oxford (1990) also points out that the use of LLS are divided into low level (1-2.4), medium use (2.5-3.4), and high use (3.5-5). In a study the 50-item SILL reported a reliability coefficient (Cronbach's Alpha Test) of .96 (Yustitiasari, Junining, \& Sahiruddin, 2020). Two studies employed an adapted 50-item SILL version which reported a reliability coefficient of .89 and .70 respectively (Ranjan \& Philominraj, 2020; Taheri, Sadighi, Bagheri \& Bavali, 2020). The SILL has been used in several studies to assess LLS, this confirms its validity (Gavriilidou \& Mitits, 2016; Lestari \& Wahyudin, 2020; Rongdara et al., 2019). For this study the SILL English language version was applied, but in a digital format because of the new normal. The reported reliability was .88 which is good (Mohammadi \& Izadpanah, 2019). The virtual SILL was used for both the pre-SILL and post-SILL, they were available on the students' university platform.

\section{Data Collection}

The data collection process took 8 weeks between the second week of May and the last week of June in 2020 (the second part of the 16 week course). Both the experimental and control group participants were told they were going to be part of a study which required responding 2 virtual surveys (pre-SILL \& post-SILL) and also 2 virtual English tests (pre-OPT \& post-OTP). Students in the experimental group were also informed that they would be part of a six week LLS program while studying their online English course. Both groups were also informed that their identities would remain anonymous, and the results would only be used for academic purposes. All participants expressed their approval to participate. The first week of the study, the participants from both groups were requested to respond the pre-SILL during their videoconference session (cameras activated) to confirm their identity and participation. Students were asked to check their course virtual platform and respond the pre-SILL items. They had up to one hour to respond it. Students were asked to reflect carefully on each item and answer as honest as possible; their answers were automatically saved. Moreover, the same week, both groups were requested to take the pre-OTP during their videoconference session; their cameras were activated while taking the test; they had one hour to do so, their answers were automatically recorded.

From second to the seventh week, the experimental group had to do activities from the language learning strategies program (LLSP), three times a week for about one hour, a total of 18 sessions. The LLSP had been previously designed based on the taxonomy and LLS exercises proposed by Oxford (1990). The main objective of the program was to make students practice the LLS while supporting their English language skills such as grammar, vocabulary, speaking, writing, listening and reading. All students were requested to have their cameras activated to see if they were actively participating. The first week of the program, students reviewed their memory strategies such as memorizing a dialog during class and present it, designing mind-maps to memorize new 
content, and trying to remember short English poems or idioms by using keywords. The second week, students had to practice their cognitive strategies, they had to elaborate a table indicating the main grammatical formulas; summarizing short texts in English using their own words. Also, highlighting the main ideas and key words from some articles. The third week, learners developed their compensation strategies by playing some games using gestures and mimes to explain characters, places, and objects, so their classmates had to guess individually or in teams. On the fourth week, in order to practice the metacognitive strategies, learners created a schedule of all the activities they usually do to practice their English after classes. Students were asked to assess their English on their own by exploring extra websites where they can take tests which include feedback. They also presented a table to the class indicating their short-term and long-term goals with regard to their English course. The following week, students explored their affective strategies by creating a list of their favorite songs in English so they can be played in class as a background. They also presented an agenda to write about their positive and funny stories when they study English. On the last week program, students practiced their social strategies by working in pairs or groups to make presentations about religion, politics and cultural heritage. Some learners shared their experience when using websites and apps to meet and communicate with native English speakers easily.

By week 8, both groups took the post-SILL and post-OPT instruments during their videoconference session (cameras activated) and had one hour to respond each instrument. During this week 25 students from both groups were randomly selected and invited for an interview, 15 students initially accepted. In the end only 10 students attended the interview ( 5 from the control group, and 5 from the experimental group), they were also told the interview was going to be done through a phone call or a WhatsApp call rather than a videoconference. For this purpose a professor, who had never been in contact with the participants before, conducted the telephone interviews to make students feel more comfortable and speak their mind about their overall online experience in the English course during that semester. Phone call interviews and telephone interviews have been used in other studies recently to collect qualitative data (Alaofi, 2020; Linnemayr, Mayo-Wilson, Saya, Wagner, MacCarthy, Walukaga, Nakubulwa \& Karamagi, 2020).

\section{Data Analysis}

The instruments quantitative results were analyzed using an independent sample t-test to assess the effect the LLSP had on the experimental group in comparison to the control group with regard to their English proficiency. Moreover, an independent sample t-test was also used to establish the effect the LLSP had on the experimental group in comparison to the control group when it comes to LLS use. The results of the instruments were also evaluated with a reliability of $95 \%$ and with an error percentage of $5 \%$, significance level 0.05 ( $\mathrm{p}<0.05$ ). For this purpose, the statistical program SPSS version 21 was used in the quantitative analysis. On the other hand, the qualitative data was taken from the structured phone interviews which were based on four questions: 1) How would you describe your overall experience in the online English course during 
COVID-19? 2) How would you describe your teacher support and feedback in the online English course during COVID-19? 3) What are the main advantages of studying the online English course during COVID-19? 4) What are the main disadvantages of studying the online English course during COVID-19? The transcription process was elaborated based on the ten students' oral responses (words) which were transcribed without paraphrasing. All transcripts were analyzed and compared using the thematic analysis so as to identify common patterns which were coded and organized into meaningful themes and insights. Other studies followed the same procedure (Dudley, O’Loughlin, Lewis, \& Loh, 2020; Tsai, 2020).

\section{FINDINGS}

The participants' main demographic characteristics are presented in Table 1. Both groups reported similar number of female and male students. Their age and the amount of time studying at the university was similar as well. Moreover, both groups reported studying different majors.

Table 1

Participants' characteristics

\begin{tabular}{lllll}
\hline & \multicolumn{2}{l}{ Experimental group } & \multicolumn{2}{l}{ Control group } \\
\hline & Male & Female & Male & Female \\
-Number of participants & 12 & 11 & 14 & 13 \\
-Age average & 18 & 18 & 19 & 18 \\
-Years studying at the university & 3 & 3 & 3 & 3 \\
-Major in Management \& Business & 5 & 5 & 4 & 6 \\
-Major in Education \& Humanities & 2 & 3 & 3 & 5 \\
-Major in Engineering & 5 & 3 & 7 & 2 \\
\hline
\end{tabular}

Table 2 shows students' English language proficiency. When the study started both groups were already in the middle of the course, so both groups reported an overall B2 command of English in the pre-OPT. Later, only the experimental group reported an overall C1 English proficiency in the post-OPT. Further details from the experimental group's pre-OPT showed that the lowest grade was 32 and the highest grade was 51, there were 10 students who achieved level B1 (marks from 30 to 38), 10 students reached B2 (marks from 41 to 47), and 3 students demonstrated C1 English proficiency (marks from 50 to 51). Similarly, the control group's pre-OPT revealed 32 as the lowest grade and 50 as the highest grade, 12 students achieved level B1 (marks from 32 to 39), 13 learners reached B2 (marks from 40 to 47), and 2 students achieved C1 English proficiency (marks from 48 to 50). On the other hand, the post-OPT results showed that the experimental group's lowest mark was 30 and the highest was 59; 3 students achieved level B1 (grades from 30 to 35), 6 students reached B2 (grades from 43 to 47), 10 students achieved $\mathrm{C} 1$ (grades from 52 to 54), and unlike the other group, 4 learners achieved C2 English proficiency (grades from 56 to 59). In contrast to this, the control group reported 31 as the lowest mark and 52 as the highest mark, there were 9 learners who achieved level B1 (grades from 31 to 39), 11 learners reached B2 (grades from 41 to 47), and 7 students achieved C1 English proficiency (grades from 48 to 51). 
Table 2

Experimental and control groups`'English proficiency results

\begin{tabular}{lllllllll}
\hline & \multicolumn{3}{l}{ Oxford Placement Test Marks } & \multicolumn{4}{l}{ English proficiency } & \\
\hline & Lowest & Highest & Average & B1 & B2 & C1 & C2 \\
Pre-OTP, experimental group & 30 & 51 & 40.26 & 10 & 10 & 3 & \\
Post-OTP, experimental group & 30 & 59 & 49.13 & 3 & 6 & 11 & 4 \\
Pre-OTP, control group & 32 & 50 & 40.63 & 12 & 13 & 2 & \\
Post-OTP, control group & 31 & 52 & 42.11 & 9 & 11 & 7 & \\
\hline
\end{tabular}

An independent sample t-test was applied to assess the effect that LLSP had on English proficiency in the experimental group (online instruction with LLSP) in comparison to the control group (online instruction only). As noted in Table 3 the experimental group reported an average pre-OPT grade of 40.26 ( $\mathrm{SD}=7.136)$ while the control group reported 40.63 points $(\mathrm{SD}=5.024)$. Additionally, the pre-OPT results from both groups were not significantly different $(\mathrm{t}=-0.214$; Df: 48 ; $\mathrm{p}>0.05)$.

Table 3

Experimental and control group-pre-OPT results

\begin{tabular}{lllllll}
\hline Group & $\mathrm{N}$ & Mean & Std.Deviation & T-value & $\begin{array}{l}\text { Degrees of } \\
\text { freedom }\end{array}$ & P-value \\
\hline Experimental & 23 & 40.26 & 7.136 & -0.214 & 48 & 0.832 \\
Control & 27 & 40.63 & 5.024 & & & \\
\hline
\end{tabular}

According to Table 4 the experimental group reported an average post-OPT grade of $49.13(\mathrm{SD}=7.898)$ while the control group reported of 42.11 points ( $\mathrm{SD}=6.091$ ). Moreover, the post-OPT results from both groups were significantly different $(\mathrm{t}=3.545$; Df: $48 ; \mathrm{p}=<0.05)$.

Table 4

Experimental and control group-post-OPT results

\begin{tabular}{lcccccc}
\hline Group & $\mathrm{N}$ & Mean & Std.Deviation & T-value & $\begin{array}{l}\text { Degrees of } \\
\text { freedom }\end{array}$ & P-value \\
\hline Experimental & 23 & 49.13 & 7.898 & 3.545 & 48 & 0.001 \\
Control & 27 & 42.11 & 6.091 & & & \\
\hline
\end{tabular}

With regard to students' LLS, an independent sample t-test was applied to both, the experimental group (online instruction with the LLS program) in comparison to the control group (online instruction only). As noted in Table 5 the pre-SILL results reveal that both groups demonstrated having a high use of metacognitive strategies, while they reported a medium use for the rest of LLS. In the case of memory strategies pre-SILL results, the experimental group reported $\mathrm{M}=3.03$ ( $\mathrm{SD}=0.403$ ) while the control group reported $\mathrm{M}=3.00$ ( $\mathrm{SD}=0.599$ ). Additionally, the results from both groups were not significantly different $(t=0.230$; Df: $48 ; p>0.05)$. When it comes to cognitive strategies pre-SILL results, the experimental group reported $\mathrm{M}=3.21$ ( $\mathrm{SD}=0.435)$ while the control group reported $\mathrm{M}=3.21$ as well $(\mathrm{SD}=0.596)$. Besides, the results from both groups were 
not significantly different ( $\mathrm{t}=0.000 ;$ Df: $48 ; \mathrm{p}>0.0 .5)$. Regarding compensation strategies pre-SILL results, the experimental group reported $\mathrm{M}=3.20(\mathrm{SD}=0.536)$ while the control group reported $\mathrm{M}=3.09$ ( $\mathrm{SD}=0.680$ ). Furthermore, the results from both groups were not significantly different $(\mathrm{t}=0.588$; Df: $48 ; \mathrm{p}>0.0 .5)$. In the case of metacognitive strategies pre-SILL results, the experimental group reported $\mathrm{M}=3.50$ $(\mathrm{SD}=0.677$ ) while the control group reported $\mathrm{M}=3.51$ ( $\mathrm{SD}=0.526)$. Additionally, the results from both groups were not significantly different $(t=0.070 ;$ Df: $48 ; p>0.05)$. When it comes to affective strategies pre-SILL results, the experimental group reported $\mathrm{M}=3.21$ ( $\mathrm{SD}=0.530$ ) while the control group reported $\mathrm{M}=3.31$ ( $\mathrm{SD}=0.569)$. Moreover, the results from both groups were not significantly different ( $t=-0.629 ; \mathrm{Df}: 48 ; \mathrm{p}>0.0 .5)$. Regarding social strategies pre-SILL results, the experimental group reported $M=3.30$ ( $\mathrm{SD}=0.682$ ) while the control group reported $\mathrm{M}=3.18$ ( $\mathrm{SD}=0.594)$. Furthermore, the results from both groups were not significantly different ( $t=0.655$; Df: 48 ; $p>0.0 .5$ ).

Table 5

Experimental and control group-pre-SILL results

\begin{tabular}{lllllllll}
\hline Group & N & LLS & Mean & LLS Use & SD & T-value & Df & P-value \\
\hline Experimental & 23 & Memory & 3.03 & Medium & 0.403 & 0.230 & 48 & 0.819 \\
\hline Control & 27 & & 3.00 & Medium & 0.599 & & & \\
\hline Experimental & 23 & Cognitive & 3.21 & Medium & 0.435 & 0.000 & 48 & 1.000 \\
\hline Control & 27 & & 3.21 & Medium & 0.596 & & & \\
\hline Experimental & 23 & Compensation & 3.20 & Medium & 0.536 & 0.588 & 48 & 0.559 \\
\hline Control & 27 & & 3.09 & Medium & 0.680 & & & \\
\hline Experimental & 23 & Metacognitive & 3.50 & High & 0.677 & 0.070 & 48 & 0.944 \\
\hline Control & 27 & & 3.51 & High & 0.526 & & & \\
\hline Experimental & 23 & Affective & 3.21 & Medium & 0.530 & -0.629 & 48 & 0.532 \\
\hline Control & 27 & & 3.31 & Medium & 0.569 & & & \\
\hline Experimental & 23 & Social & 3.30 & Medium & 0.682 & 0.655 & 48 & 0.516 \\
\hline Control & 27 & & 3.18 & Medium & 0.594 & & & \\
\hline
\end{tabular}

As noted in Table 6 the post-SILL results show that the experimental group demonstrated having a high use of cognitive, compensation, metacognitive, social and affective strategies while memory strategies were the least used. And the control group demonstrated having a medium use in all LLS. In the case of memory strategies postSILL results, the experimental group reported $\mathrm{M}=3.38(\mathrm{SD}=0.400)$ while the control group reported $\mathrm{M}=2.88$ ( $\mathrm{SD}=0.600$ ). Additionally, the results from both groups were significantly different $(\mathrm{t}=3.378 ; \mathrm{Df}: 48 ; \mathrm{p}=<0.05)$. When it comes to cognitive strategies post-SILL results, the experimental group reported $\mathrm{M}=3.82(\mathrm{SD}=0.424)$ while the control group reported $\mathrm{M}=3.10$ ( $\mathrm{SD}=0.651$ ). Besides, the results from both groups were significantly different ( $\mathrm{t}=4.544$; Df: $48 ; \mathrm{p}=<0.05)$. Regarding compensation strategies post-SILL results, the experimental group reported $\mathrm{M}=3.93(\mathrm{SD}=0.555)$ while the control group reported $\mathrm{M}=3.26$ ( $\mathrm{SD}=0.572$ ). Furthermore, the results from both groups were significantly different $(\mathrm{t}=4.173$; Df: $48 ; \mathrm{p}=<0.05)$. In the case of metacognitive strategies post-SILL results, the experimental group reported $M=4.25$ 
( $\mathrm{SD}=0.388$ ) while the control group reported $\mathrm{M}=3.35$ ( $\mathrm{SD}=0.654)$. Additionally, the results from both groups were significantly different ( $\mathrm{t}=5.762$; Df: $48 ; \mathrm{p}=<0.05$ ). When it comes to affective strategies post-SILL results, the experimental group reported $\mathrm{M}=3.66$ ( $\mathrm{SD}=0.483$ ) while the control group reported $\mathrm{M}=3.48$ ( $\mathrm{SD}=0.687$ ). Moreover, the results from both groups were not significantly different ( $t=1.078$; Df: 48; $p>0.0 .5$ ). Regarding social strategies post-SILL results, the experimental group reported $M=3.72$ ( $\mathrm{SD}=0.486$ ) while the control group reported $\mathrm{M}=3.45$ ( $\mathrm{SD}=0.639)$. Furthermore, the results from both groups were not significantly different ( $t=1.683$; Df: 48; $p>0.0 .5$ ).

Table 6

Experimental and control group-post-SILL results

\begin{tabular}{lllllllll}
\hline Group & N & LLS & Mean & LLS Use & SD & T-value & Df & P-value \\
\hline Experimental & 23 & Memory & 3.38 & Medium & 0.400 & 3.378 & 48 & 0.001 \\
\hline Control & 27 & & 2.88 & Medium & 0.600 & & & \\
\hline Experimental & 23 & Cognitive & 3.82 & High & 0.424 & 4.544 & 48 & 0.000 \\
\hline Control & 27 & & 3.10 & Medium & 0.651 & & & \\
\hline Experimental & 23 & Compensation & 3.93 & High & 0.555 & 4.173 & 48 & 0.000 \\
\hline Control & 27 & & 3.26 & Medium & 0.572 & & & \\
\hline Experimental & 23 & Metacognitive & 4.25 & High & 0.388 & 5.762 & 48 & 0.000 \\
\hline Control & 27 & & 3.35 & Medium & 0.654 & & & \\
\hline Experimental & 23 & Affective & 3.66 & High & 0.483 & 1.078 & 48 & 0.287 \\
\hline Control & 27 & & 3.48 & Medium & 0.687 & & & \\
\hline Experimental & 23 & Social & 3.72 & High & 0.486 & 1.683 & 48 & 0.099 \\
\hline Control & 27 & & 3.45 & Medium & 0.639 & & & \\
\hline
\end{tabular}

Regarding the qualitative analysis from the 10 students' interviews, it was established four main themes (a) overall experience in the online English course during COVID-19 (b) perception of teacher support and feedback in the online English course during COVID-19 (c) advantages of studying the online English course during COVID-19 (d) disadvantages of studying the online English course during COVID-19.

\section{Overall experience in the online English course during COVID-19}

1. I felt good about my English learning experience (participant E).

2. I believe that the English online course has taught me many things because it has been a new experience (participant D).

3. I think that the English online learning has been fine for me (participant I).

4. I feel like overall it was a good experience in online learning (participant $\mathrm{H}$ ).

5. The English online learning experience is working overall well as much as online education can be (participant F).

6. I believe that although the course looks well designed for online sessions I particularly don't enjoy online learning (participant A). 
Perception of teacher support and feedback in the online English course during COVID-19

1. Despite of the problem that the classes have not been in person, I have learned a lot from my teacher who has been there to answer all my questions (participant D).

2. The professor was always willing to explain something that maybe wasn't clear and revise the subject again if necessary (participant $\mathrm{E}$ ).

3. Regarding support and feedback, the professor made himself available to students (participant F).

4. I feel like we have received plenty of support regarding the clarification of assignments and preparation (participant $G$ ).

5. The professor feedback was efficient, because he answered all my doubts on time when it was needed (participant $\mathrm{H}$ ).

6. The interaction between professor and student and the tools we have to contact him have been very helpful (participant I).

\section{Advantages of studying the online English course during COVID-19}

1. All the classes were recorded so when I did not understand or missed something I would go and watch the recorded sessions (participant $\mathrm{H}$ ).

2. In terms of the course design, I find the course well-structured which facilitates learning (participant F).

3. I think that overall, the course design was good taking in consideration the current situation (participant $\mathrm{G}$ ).

4. Although communication was not as interactive as in regular classes, the platform interaction was positive, since it worked well in spreading information about the assignments and topics (participant $\mathrm{J}$ ).

5. Online learning helped me a lot to participate more and put more effort on learning (participant I).

\section{Disadvantages of studying the online English course during COVID-19}

1. I normally had a good internet connection, however there are some instances in which I connected late to a session because I lost connection (participant A).

2. Sometimes I have issues due to my Wi-Fi connection but nothing that affect notable my class development (participant $\mathrm{C}$ ).

3. As of my Wi-Fi connection I can say it is in the majority of cases good, but sometimes the connection goes off (participant F).

4. I must admit that a big challenge for me was the Wi-Fi connection because mine was not good enough in terms of working actively in every class (participant $\mathrm{H}$ ). 
5. I had internet issues and laptop issues sometimes (participant I).

6. It took me time to adapt to this new system (participant J).

7. I think the English course' official tests design was not totally efficient because we used to have more time to take exams, but I think that many professors believe that we will cheat when it is not the case (participant B).

\section{DISCUSSION}

It is reported that online language learners develop some strategies or self-regulating skills as to establish goals, seek help and evaluate their learning (Tao et al., 2020). The findings of this longitudinal study reveal that when a group of students is directly exposed to a variety of LLS activities for a period of time, their LLS mostly increase from medium to high LLS use. On the contrary, when LLS are not actively put into practice in another class group, they do not vary significantly or slightly decrease over time. However, in other cross-sectional studies, developed in face-to-face settings, learners reported similar LLS results as this study (Habók \& Magyar, 2018; Iamudom \& Tangkiengsirisin, 2020; Ranjan \& Philominraj, 2020; Taheri et al., 2020). Therefore, students' use of LLS do not seem to vary significantly in face-to-face or digital scenarios. Also, both scenarios seem to provide the same opportunities for students to use their preferred LLS.

The findings of this study also support that both groups have a high preference for metacognitive strategies, like their counterparts who study in face-to-face courses. Therefore, it seems that online learners prefer metacognitive strategies over others and they do not depend on being directly taught these strategies to put them into practice. Notwithstanding, other LLS seem to benefit from being practiced in class resulting in a higher use of them after some period of time. Moreover, in other face-to-face university scenarios where no LLS program is applied, students report a high use of both social and metacognitive strategies while the rest of strategies are reported as medium use (Ranjan \& Philominraj, 2020); highly users of metacognitive, social, and compensation strategies while medium users of cognitive, memory, and affective strategies (Lestari \& Wahyudin, 2020). And in other cases, medium users in all strategies (Alhaysony, 2017) as well as high users of all LLS (Lestari \& Fatimah, 2020). This can be interpreted as a pattern in higher education suggesting that students tend to be both medium and high LLS users regardless of the means of instruction whether face-to-face or online.

With regard to English proficiency differences between the study's groups. The experimental group reported improving from B2 to $\mathrm{C} 1$ level while the control group remained in B2 level. The findings suggest that students' English proficiency can be affected by the implementation of a LLS program if it is designed to support and be part of the course tasks. This could indicate that incorporating LLS activities in online language courses present some pedagogical benefits (Lin, Zhang \& Zheng, 2017). Using LLS exercises in an online course can be helpful for students' language proficiency development. On the other hand, despite the initial OTP grades which showed similar results in both groups (B2 level), each group reported different levels of English or weak and strong students (B1, B2 \& C1 level). A similar pattern was also noticed in the 
post OTP grades, the control group (B1, B2 \& C level) and the experimental group (B1, B2, C1 \& C2 level). This could also suggest that students' language proficiency may be also affected by other external factors apart from the online course content and LLS activities. Additionally, even though this study results are as similar as other studies which also used the OPT to assess language proficiency in terms of grammar, vocabulary and reading skills (Enayat, \& Amirian, 2016; Mohammadi \& Izadpanah 2019; Tavakoli et al, 2014), this test seems to be limited to assess other aspects of language proficiency such as speaking, writing and listening which can also provide a broader picture of students' English proficiency (Arisman, 2020; Tavakoli et al, 2014).

The themes from the qualitative analysis suggest that the participants overall experience in the online English course during COVID-19 seems to be positive; however, this is not the same case as in other online instruction contexts where students seem to have had a harder time on their online learning experience (Crawford et al., 2020; Demuyakor, 2020). On the other hand, the students' positive comments about their online English course may be the result of their university's previous experience with designing online programs; this suggests that not all universities have been equally prepared to embrace fully online courses (Crawford et al., 2020). Additionally, students' positive perception about their teacher feedback also reveal that an effective online pedagogy is an essential component of online courses in order to guarantee students effective guidance and the course academic standards (Crawford et al., 2020; Dhawan, 2020) also self-regulation skills or online learning strategies (Demuyakor, 2020; Lin, Zhang \& Zheng, 2017).

Regarding the advantages of studying the online English course, learners seem to like their classes being recorded, the course design, and the tools to participate and communicate in class. This suggests that online instruction needs to provide the course content availability, innovative course design, and critical thinking tasks (Dhawan, 2020). When it comes to disadvantages of studying on the online English course, students report as their main problem the occasional Wi-Fi connectivity issues, the adaptation to the new system, and dissatisfaction with new exam formats. Therefore, educational institutions should verify both teachers and students count with the proper internet connection and tech training to be part of the online experience; teachers should also be flexible in dealing with students' feelings such as frustration, anxiety, confusion and distraction (Dhawan, 2020).

\section{CONCLUSIONS}

In a nutshell, this study has contributed to research in LLS, English proficiency and English instruction in online settings during the new normal. It is concluded that incorporating LLS in online English courses have some pedagogical implications since LLS tasks can improve English proficiency. Language learners not only have the opportunity to learn English traditionally (whether face-to-face or online) but also benefit from having in class tasks with regard to memory, cognitive, compensation, metacognitive, affective, and social strategies which can be applied individually, in pairs or groups. Therefore, LLS can support students' language learning, encourage learners' engagement to participate in class especially in online lessons. 
Even though the sample consisted of 50 undergraduate students whose quantitative data cannot be generalized in other learning contexts, the statistical results were quite significant and can be taken as a reference for future research. The study's qualitative data also suggests that the transition from face-to-face to online modules can be done successfully since most of the course content can be fully digitalized making the online instruction a positive experience.

Finally, to contrast the results of this research, new studies can be done with larger samples, samples with a different command of English or another language. Other instruments can be applied to evaluate the study's variables. Maybe adapting the SILL, whether a shorter version or using the student mother tongue. Also using another English proficiency test which takes into consideration more language skills. Moreover, using other qualitative instruments to understand students' perception about their online instruction experience during the new normal.

\section{ACKNOWLEDGMENT}

This study has been financed by the Dirección de Investigación de la Universidad Peruana de Ciencias Aplicadas. Project: A-090-2020.

\section{REFERENCES}

Alaofi, A. O. (2020). Difficulties of Summarizing and Paraphrasing in English as a Foreign Language (EFL): Saudi Graduate Students' Perspectives. International Journal of English Language Education, 8(2), 193-211. https://doi.org/10.5296/ijele.v 8 i 217 788

Alhaysony, M. (2017). Language learning strategies use by Saudi EFL students: The effect of duration of English language study and gender. Theory and Practice in Language Studies, 7(1), 18-28. doi: http://dx.doi.org/10.17507/tpls.0701.03

Arisman, R. (2020). The Relationship between Direct Language Learning Strategies and English Learning Proficiency at Senior High School Students. J-SHMIC: Journal of English for Academic, 7(2), 41-51.

Aziz, S. N., \& Shah, P. M. (2020). Language Learning Strategy (LLS) for English Language Learners in Polytechnic. Journal of Personalized Learning, 3(1), 71-78.

Burdina, M.G., Krapotkina, I. E., \& Nasyrova, L. G. (2019). Distance Learning in Elementary School Classrooms: An Emerging Framework for Contemporary Practice. International Journal of Instruction, 12(1), 1-16. https://doi.org/10.29333/iji.2019.1211a

Crawford, J., Butler-Henderson, K., Rudolph, J., Malkawi, B., Glowatz, M., Burton, R., Magni, P. \& Lam, S. (2020). COVID-19: 20 countries' higher education intra-period digital pedagogy responses. Journal of Applied Learning \& Teaching, 3(1), 1-20. https://doi.org/10.37074/jalt.2020.3.1.7 
Council of Europe (2020). Common European Framework of Reference for Languages: Learning, Teaching, Assessment (CEFR).https://www.coe.int/en/web/commoneuropean-framework-reference-languages

Daif-Allah, A. S., \& Aljumah, F. H. (2020). Differences in Motivation to Learning English among Saudi University Students. English Language Teaching, 13(2), 63-74. https://doi.org/10.5539/elt.v13n2p63

Demuyakor, J. (2020). Coronavirus (COVID-19) and Online Learning in Higher Institutions of Education: A Survey of the Perceptions of Ghanaian International Students in China. Online Journal of Communication and Media Technologies, 10(3), e202018. https://doi.org/10.29333/ojcmt/8286

Dhawan, S. (2020). Online learning: A panacea in the time of COVID-19 crisis. Journal of Educational Technology Systems, 49(1), 5-22. doi: 10.1177/0047239520934018

Dudley, D., O'Loughlin, K., Lewis, S., \& Loh, V. (2020). Retirees' perceptions of goal setting: A qualitative study. Australasian Journal on Ageing, 39(3), 1-8. https://doi.org/10.1111/ajag.12798

Enayat, M. J., \& Amirian, S. M. R. (2016). Vocabulary Levels Test and Word Associates Test: Can they Measure Language Proficiency?. Asian Journal of Assessment in Teaching and Learning, 6, 17-26. https://ejournal.upsi.edu.my/index.php/AJATeL/article/view/1975

Gavriilidou, Z., \& Mitits, L. (2016). Adaptation of the Strategy Inventory for Language Learning (SILL) for students aged 12-15 into Greek: Developing an adaptation protocol. Selected papers on theoretical and applied linguistics, 21, 588-601. doi: https://doi.org/10.26262/istal.v21i0.5256

Habók, A., \& Magyar, A. (2018). The effect of language learning strategies on proficiency, attitudes and school achievement. Frontiers in psychology, 8, 1-8. doi: 10.3389/fpsyg.2017.02358

Hastuti, I. D., Surahmat, Sutarto, \& Dafik. (2020). The Effect of Guided Inquiry Learning in Improving Metacognitive Skill of Elementary School Students. International Journal of Instruction,13(4), 315-330. https://doi.org/10.29333/iji.2020.13420a

Iamudom, T., \& Tangkiengsirisin, S. (2020). A Comparison Study of Learner Autonomy and Language Learning Strategies among Thai EFL Learners. International Journal of Instruction, 13(2),199-212. https://doi.org/10.29333/iji.2020.13214a

Lestari, T. M., \& Fatimah, S. (2020). An Analysis of Language Learning Strategies Used by EFL Student Teachers at English Language Education Program Universitas Negeri Padang. Journal of English Language Teaching, 9(1), 333-345.

Lestari, M. \& Wahyudin, A. Y. (2020). Language Learning Strategies of Undergraduate EFL Students. Journal of English Language Teaching and Learning, 1(1), 25-30. 
Linnemayr, S., Mayo-Wilson, L. J., Saya, U., Wagner, Z., MacCarthy, S., Walukaga, S., Nakubulwa, S. \& Karamagi, Y. (2020). HIV Care Experiences During the COVID-19 Pandemic: Mixed-Methods Telephone Interviews with Clinic-Enrolled HIV-Infected Adults in Uganda. AIDS and Behavior, 1(12). https://doi.org/10.1007/s10461-02003032-8

Lin, C. H., Zhang, Y., \& Zheng, B. (2017). The roles of learning strategies and motivation in online language learning: A structural equation modeling analysis. Computers \& Education, 113, 75-85. http://dx.doi.org/10.1016/j.compedu.2017.05.014

Louis-Jean, J., \& Cenat, K. (2020). Beyond the Face-to-Face Learning: A Contextual Analysis. Pedagogical Research, 5(4), em0077. https://doi.org/10.29333/pr/8466

Mohammadi, H., \& Izadpanah, S. (2019). A Study of the Relationship between Iranian Learners' Sociocultural Identity and English as a Foreign Language (EFL) Learning Proficiency. International Journal of Instruction, 12(1), 53-68.

Murphy, L., Eduljee, N. B., \& Croteau, K. (2020). College Student Transition to Synchronous Virtual Classes during the COVID-19 Pandemic in Northeastern United States. Pedagogical Research, 5(4), em0078. https://doi.org/10.29333/pr/8485

Oxford, R. (1990). Language learning strategies: What every teacher should know. Boston: Heinle \& Heinle Publishers.

Ranjan, R., \& Philominraj, A. (2020). Language Learning Strategies, Motivation and Gender in Foreign Language Context. Universal Journal of Educational Research, 8(2), 591-604. doi: 10.13189/ujer.2020.080231

Rongdara, R., Liew, K. L., Masturah, S., \& Kanya, P. (2019). Comparative study of language learning strategies used by first-year students at Prince of Songkla University, Pattani Campus, Thailand and UniMAP, Malaysia. Journal of Communication in Scientific Inquiry, 1(1), 1-8.

Santoveña-Casal, S., \& Bernal-Bravo, C. (2019). Explorando la influencia del docente: Participación social en Twitter y percepción académica. Comunicar: Revista Científica de Comunicación y Educación, 27(58), 75-84. https://doi.org/10.3916/C58-2019-07

Shakarami, A., Hajhashemi, K. \& Caltabiano, N.J. (2017). Compensation still matters: Language learning strategies in third millennium ESL learners. Online Learning, 21(3), 235-250.doi: 10.24059/olj.v21i3.1055

Taheri, H., Sadighi, F., Bagheri, M. S., \& Bavali, M. (2020). Investigating the relationship between Iranian EFL learners' use of language learning strategies and foreign language skills achievement. Cogent Arts \& Humanities, 7(1), 1710944. https://doi.org/10.1080/23311983.2019.1710944

Tao, J., Zheng, C., Lu, Z., Liang, J. C., \& Tsai, C. C. (2020). Cluster analysis on Chinese university students' conceptions of English language learning and their online self-regulation. Australasian Journal of Educational Technology, 36(2), 105-119. 
Tavakoli, Z., Rakhshanderoo, F., Izadpanah, M., \& Moradi, M. (2014). Ego identity types and language proficiency of Iranian EFL learners. Procedia-Social and Behavioral Sciences, 98, 1885-1894. doi: 10.1016/j.sbspro.2014.03.619

Thapa, S., Rai, N., Adhikari, J., Ghimire, A., Limbu, A. K., Joshi, A., \& Adhikari, S. (2020). Impact of COVID-19 Lockdown on Agriculture Education in Nepal: An Online survey. Pedagogical Research, 5(4), em0076. https://doi.org/10.29333/pr/8465

Toepoel, V. (2017). Online survey design. In N. G. Fielding, R. M. Lee \& G. Blank, (Eds.), The SAGE Handbook of Online Research Methods (2nd ed., pp. 184-202). SAGE Publications Ltd. https://dx.doi.org/10.4135/9781473957992.n11

Toquero, C. M. (2020). Challenges and Opportunities for Higher Education amid the COVID-19 Pandemic: The Philippine Context. Pedagogical Research, 5(4), em0063. https://doi.org/10.29333/pr/7947

Tsai, C-C. (2020). The Effects of Augmented Reality to Motivation and Performance in EFL Vocabulary Learning. International Journal of Instruction, 13(4), 9871000.https://doi.org/10.29333/iji.2020.13460a

Yustitiasari, H., Junining, E., \& Sahiruddin, S. (2020). The relationship between language learning strategies used by vocational students and level of proficiency. $e$ Journal of Linguistics, 14(1), 128-136. https://doi.org/10.24843/e-j1.2020.v14.i01.p013 